\title{
Effects of a tailor-made exercise program on exercise adherence and health outcomes in patients with knee osteoarthritis: a mixed-methods pilot study
}

\author{
This article was published in the following Dove Press journal: \\ Clinical Interventions in Aging \\ 5 October 2016 \\ Number of times this article has been viewed
}

\section{Fung-Kam Iris Lee \\ Tze-Fan Diana Lee \\ Winnie Kwok-Wei So}

The Nethersole School of Nursing, The Chinese University of Hong Kong, Hong Kong, SAR China
Correspondence: Fung-Kam Iris Lee The Nethersole School of Nursing, Room 730, Esther Lee Building, The Chinese University of Hong Kong, Shatin, New Territories, Hong Kong, SAR China

Tel +8523943 6228

Fax +852 26035269

Email fk95lee@cuhk.edu.hk
Introduction: Previous studies showed that exercise intervention was effective in symptoms control of knee osteoarthritis (OA) but poor intervention adherence reduced the exercise effect. It has been suspected that the design of exercise intervention mainly from the health care professionals' perspective could not address the patients' barriers to exercise. Therefore, a tailor-made exercise program which incorporated the patient's perspective in the design was developed and ready for evaluation.

Objectives: This pilot study estimated the effects of a tailor-made exercise program on exercise adherence and health outcomes, and explored the participants' perception and experience of the program.

Methods: The intervention of this study was a 4-week community-based group exercise program, which required the participants to attend a 1-hour session each week. Thirty-four older people with knee OA were recruited to the program. Mixed-methods study design was used to estimate the effects of this program and explore the participants' perception and experience of the program. Exercise adherence and performance in return-demonstration of the exercise were assessed at 12 weeks after the program. Disease-specific health status (Western Ontario and McMaster Universities Osteoarthritis Index), general health status (12-item Short Form of the Medical Outcome Study Questionnaire), knee range of motion, muscle strength, and endurance of the lower extremities (Timed-Stands Test) were measured at the beginning of the program and 12 weeks after. Six participants were interviewed individually on the 12 th week.

Results: Thirty-three participants ( $75.0 \pm 7.3$ years) completed the one-group pretest and posttest study. The participants' exercise adherence was $91.4 \% \pm 14.54 \%$, and their correct performance in return-demonstration was $76.7 \% \pm 21.75 \%$. Most of the participants' health outcomes significantly improved at posttests except the 12-item Short Form of the Medical Outcome Study Questionnaire physical health summary score. The qualitative findings provided rich information to explain and support the quantitative results.

Conclusion: The results of this study showed that a tailor-made exercise program could improve exercise adherence and health outcomes in older people with knee OA.

Keywords: Hong Kong, exercise intervention, Chinese, community-based program, older people

\section{Introduction}

Osteoarthritis (OA) is the most common joint condition, and a major cause of musculoskeletal pain and disability, in the elderly population. ${ }^{1}$ Knee OA is more 
common than $\mathrm{OA}$ in other joints, and the lifetime risk for symptomatic knee OA has been reported to be $44.7 \%{ }^{2}$ The primary goals of knee OA management are to reduce pain, and to improve physical functioning and the health-related quality of life. Among the various treatment modalities, exercise is recommended as the first line of choice in clinical guidelines for the management of knee OA. ${ }^{3,4}$ The significance of the treatment effect of exercise is similar to that of pharmacological treatment in terms of the reduction of pain. ${ }^{5}$ Exercise may have the advantage over pharmacological treatment because it also improves the person's physical functioning and fitness through muscle training. ${ }^{6}$ To sustain the effect of exercise, exercise adherence is important, but it is common for exercise adherence to decrease over time. ${ }^{7-9}$

Exercise intervention can be defined as a range of physical activities involving muscular contraction and repetitive bodily movement that is planned, structured, and purposely aimed at improving one or more components of physical fitness. ${ }^{10}$ Exercise intervention is a general concept that can have many variations such as different modes (eg, various types of exercises), dosages (eg, intensity, duration, frequency), and delivery methods (eg, individualized, classbased, home-based). According to the recommendation of the American College of Rheumatology (ACR) ${ }^{11}$ and Arthritis Foundation (AF), ${ }^{12}$ and Osteoarthritis Research Society International guidelines for people with knee OA, ${ }^{3}$ aerobic exercise, strengthening exercise, flexibility exercise, and neuromuscular training such as agility and perturbation training ${ }^{13,14}$ should be prescribed to people with knee OA. In knee OA, priority of exercise prescription should be given to regain the client's knee flexibility, muscle strength, and neuromuscular control, as these impairments are the primary causes of difficulties in physical functioning. ${ }^{13,15}$

Abundant research has been carried out on testing and summarizing the effectiveness of exercise interventions for people suffering from knee OA. ${ }^{13,14,16-19}$ The beneficial effects of exercise interventions on the health of people with knee OA, such as a reduction of knee pain and physical disability, were consistently demonstrated. Previous studies also attempted to identify how long the exercise effects would last after the exercise intervention stopped. ${ }^{20}$ However, the results varied from one study to another as the exercise programs used in these studies were heterogeneous. The most consistent conclusion reached in these studies, however, was that the exercise effect would eventually disappear if the exercise regimen was discontinued.

Individuals of different communities may have their unique barriers for exercise adherence, for example, cultural beliefs and contextual barriers. ${ }^{21}$ Therefore, understanding exercise barriers from the patient's perspective is important in order to promote exercise adherence. ${ }^{22}$ However, previous exercise intervention study on older people with knee OA seldom reported using information from the patient's perspective in the design of an exercise program.

In view of this underreported research area, a qualitative study with 31 older people with knee OA was carried out to explore their perceptions and experience of exercise. ${ }^{23}$ The patient's beliefs about exercise, experiences of using exercise in daily management of knee OA, and also their facilitators and barriers for participating in an exercise program and continuation of prescribed home exercise were revealed in the study findings. The patient's beliefs about exercise and living context, knowledge and skills for exercise, and physical and mental capacity for participating in an exercise program and integrating therapeutic exercise regimen in daily living were identified and considered in the development of an exercise program. This paper reports the results of a pilot study that evaluated this exercise program.

\section{Materials and methods Study design, aim, and objectives}

A mixed-methods study was performed for piloting a tailormade exercise program which aimed at promoting adherence among older people with knee OA. This study consisted of a one-group pretest and posttest study and a post-intervention exploratory qualitative study. The objectives of this study were to estimate the effects of the exercise program on exercise adherence and health outcomes, and to explore the participants' experience and perception of the program. This study was approved by the research ethics committee of The Chinese University of Hong Kong and complied with the Declaration of Helsinki. All the participants provided informed written consent to the study.

\section{Participants}

Thirty-four older people with knee OA were recruited by using convenience sampling from a community center for older people in Hong Kong. The sample inclusion criteria included individuals who were aged $\geq 60$ years, fulfilled the ACR's clinical criteria for the classification of knee OA, ${ }^{24}$ and were living at home. The exclusion criteria included participation in other exercise programs provided by health care professionals on a regular basis, treatment with intraarticular steroid or hyaluronate injection in the previous month, concurrent acupuncture treatment, the presence of hip OA, rheumatoid arthritis, or other inflammatory joint disease, a history of surgical procedures on the lower extremity in the previous 6 months, and the presence of comorbidity 
which contraindicated the exercise program. Six participants, who had completed the exercise program, were able to articulate their views, and had different demographics and responses toward the program, for example, different levels of satisfaction, exercise adherence, and performance, were purposively selected for providing perceptions and experiences of the program.

\section{Exercise program}

The exercise program of this study was developed by incorporating the patient's perspective into its design; thus, it was tailor-made to meet the common needs of the patients living in that community. The content and delivery method of the exercise program was the same for all the participants.

The content of the program included a wide range of knowledge related to knee OA and exercise (eg, signs and symptoms of knee OA, treatment options, benefits of exercise, general guidelines about exercise for older people with knee OA, different types of exercises, and the corresponding therapeutic effects on knee OA), and a home exercise regimen. The knowledge content gave consideration to the patients' lack of knowledge of the subject and misunderstandings about the effect of exercise in their beliefs. In the general guidelines about exercise, elderly participants were reminded that exercise is contraindicated during inflammatory periods because exercise can worsen the inflammatory process. The elderly participants could consult the instructor for any concerns that arose from doing the exercise, via center staff.

A set of the home exercise regimen consisted of seven exercises: two knee range-of-motion (ROM) exercises (raise the leg and kick back to the optimal ROM in sitting position), two stretching exercises (stretch the back of knee in sitting position and the calf in standing position by holding the stretching position for 10 seconds), and three musclestrengthening exercises (raise the leg with resistance band in sitting position and hold the position for 5 seconds, squat to $30^{\circ}$ from the vertical plane and hold the position for 5 seconds, and rise up from the chair). Ten repetitions were expected to be performed in each set, and the participant was expected to perform two sets per day, 7 days per week. Each set could be completed in 20-25 minutes at a low-to-moderate exercise intensity level. The prescription of exercise was based on the guidelines provided by the $\mathrm{ACR}^{11}$ and $\mathrm{AF},{ }^{12}$ the principles of exercise prescription, ${ }^{10,13}$ the results of randomized controlled trials, ${ }^{25-30}$ and the expert opinions from two experienced physiotherapists, took consideration of the patient's physical and mental capacity as well as their living context (eg, lifestyle and physical living environment). It was designed to be light, simple, and flexible enough to be practiced both at home and at an outside venue.

The exercise program was designed to have four 1-hour weekly group teaching sessions at a community center for older people. It was delivered by a health care professional with special training on teaching exercise to older people. The group size was eight to ten people. Four identical classes of the exercise program were carried out at different time slots of a week, and participants were allowed to attend classes in time slots which were not originally assigned to them. In the design, the patient's living context, for example, tight and unstable time schedule, and established peer support at the local community center were considered.

The content of the program was delivered with the assistance of audio-visual materials, for example, PowerPoint slides, pamphlet, and poster. Exercises were taught by life-demonstration, practice, and return-demonstration, and two to three exercises were taught in each session. In addition, there was time for exercise revision and a short discussion on how to carry out the exercise in daily living, in each session except the first session. The participants were advised to practice the home exercise regimen by themselves. Pamphlet and poster were used in the program for assisting the participants' self-practice of the home exercise regimen. The pamphlet provided detailed descriptions of how to perform the exercise movements and the general guidelines about exercise for older people with knee OA. The poster consisted of mainly pictures of the exercise movements. The content delivery methods took consideration of the patient's learning style.

The program was developed in consultation with a panel of experts including two physiotherapists, a sport scientist, a medical officer, a Traditional Chinese Medicine practitioner, a social worker, and a community geriatric nurse.

\section{Exercise adherence}

Exercise adherence in terms of exercise frequency was assessed at 12 weeks after the program. Exercise adherence was measured by comparing the participant's frequency of practice for each exercise movement in a day to the recommended frequency in the design of the home exercise regimen. Each participant was supplied with an exercise diary for recording the frequency of performing each of the recommended exercises and the reason for not performing the exercise. The exercise diary was designed in calendar format with pictures of the exercise movements on the first column, and the participant was requested to check the boxes for each of the seven exercise movements twice. The exercise diary was collected at 12 weeks after the exercise program. 


\section{Exercise performance}

Performance in return-demonstration of the exercise was assessed at 12 weeks after the program. The participant's performance in return-demonstration of the seven home exercise movements was individually assessed by the health care professional who taught the exercise using a checklist developed by the research team, and the final rating ranged from 0 to 100; a higher rating indicated a better mastering of the exercise movements.

\section{Health outcomes}

Health outcomes on disease-specific health status, general health status, knee ROM, and muscle strength and endurance of the lower extremities were measured by using Western Ontario and McMaster Universities Osteoarthritis Index (WOMAC) - Hong Kong version, 12-item Short Form of the Medical Outcome Study Questionnaire (SF-12) Chinese (Hong Kong) standard version 2, a goniometer with the scale measuring to the nearest one-tenth of a degree, and the Timed-Stands Test (TST), respectively. The WOMAC consists of 24 items (five in pain, two in stiffness, 17 in physical functioning), yielding reports on the severity of symptoms of the affected joint. The transformed subscale and total scale scores range from 0 to $100 .{ }^{31} \mathrm{It}$ is a well-validated instrument. ${ }^{32,33}$ The SF-12 is a generic self-reported health status questionnaire, consisting of 12 questions measuring both physical and mental health status. The transformed scale scores range from 0 to $100 .{ }^{34}$ The Physical Health Summary Scale and Mental Health Summary Scale can be produced by using the validated formulas for the community of the participants. ${ }^{35}$ These scale scores, respectively, indicate the physical and mental aspects of the general health status of the respondent. The psychometric properties of SF-12 are well documented. ${ }^{36-39}$ The TST is delivered by requesting the individual to stand up and sit down ten times from a stable chair by using mainly the muscle strength of the lower extremities. The chair should allow the individual to rest the feet completely on the ground and to keep the knees bent to slightly $<90^{\circ}$. The participants' health outcomes were collected upon their enrollment into the study and also at 12 weeks after the exercise program.

\section{Program satisfaction}

A ten-item satisfaction questionnaire was developed by us for assessing the participants' satisfaction with the content, speaker, teaching methods, and class and venue arrangement of the program, and also the participants' confidence in learning, memorizing, and continual practicing of the exercise movements. The participants were asked to respond on a five-point Likert scale ranging from " 0 " for "strongly disagree" to "4" for "strongly agree" with the item. A total original score ranging from 0 to 40 was transformed into a 0-100 score for easy interpretation. The satisfaction questionnaire was administered at the end of the last class session by part-time research assistants who were not involved in teaching the program.

\section{Perceptions and experiences of the program}

A semi-structured interview guide was used for guiding the individual face-to-face interviews in a room at the community center. Areas of focus included the participants' views toward the program, their experience of participating in the program, and their experience of integrating the exercise into daily routine. All the interviews were carried out by a research assistant who was very experienced in conducting qualitative interviews, and the research assistant did not participate in teaching of the exercise program. All the interviews were conducted within 2 weeks after the posttest session and audio-recorded.

\section{Demographic and clinical data}

Demographic and clinical data including age, sex, educational level, marital status, type of residence, living arrangements, employment status, social assistance, exercise habits, medical follow-up for knee OA, duration of symptoms, bilaterality of symptoms, use of walking aids, body weight, body height, and chronic comorbidities were collected for each participant upon enrollment into the study.

\section{Data analyses}

Descriptive statistical analyses were used to describe the participants' characteristics and summarize their exercise adherence, performance, and satisfaction with the exercise program. Wilcoxon signed rank test was used to identify the participants' changes in health outcomes before and 12 weeks after the exercise program. The level of significance set for this study was 0.05 . Content analysis was employed to analyze the interview data. The audio-recorded interviews were firstly transcribed verbatim, and each piece of the transcription was checked against the audio records to ensure its accuracy. The principal researcher reviewed the transcriptions line by line within the context of the entire interview to identify and code significant patterns. 
The emerging themes from the identified patterns were developed into major categories. Checking of objectivity in the development of themes and categories was carried out by inviting another researcher to read two randomly selected transcriptions and develop themes and categories independently.

\section{Results}

Among the 34 older people who were recruited into this study, one participant dropped out from the study due to loss of contact after the first session. Therefore, there were 33 participants in the final sample who completed the onegroup pretest and posttest study. The characteristics of the final sample are presented in Table 1. Seventeen participants $(51.5 \%)$ were frail elders ( $>75$ years old). Mann-Whitney $U$-tests were performed to compare the frail elders with the younger participants ( $\leq 75$ years) for their responses to the program (exercise adherence and performance, and satisfaction with the program) and health outcomes. The results did not reveal any significant difference between the two groups. As the duration of knee OA symptoms of participants varied from 0.2 to 30 years, Spearman's rho correlation coefficients were used to identify any significant relationship between duration of knee OA symptoms and the responses to the program and between duration of knee OA symptoms and the health outcomes; no statistically significant correlation was noted. Mann-Whitney $U$-tests were also performed to compare between participants who had heart disease/COPD and those who did not for their responses to the program and health outcomes. The results did not identify any significant difference between the two groups. About $70 \%$ of participants had regular exercise habits which mainly included flexing limbs and trunks, swinging arms and legs, and moving the body about. Mann-Whitney $U$-tests were performed to compare participants who had regular exercise habits with those who did not for their responses to the program and health outcomes. The result did not show any significant difference between the two groups.

Four female and two male participants who had completed the study were interviewed face to face and individually after the posttest for their perceptions and experience of the exercise program.

Twenty-seven participants fully attended the exercise program, and the other six participants missed one session, which resulted in a $95 \%$ attendance rate. The reasons for the participants' absence from the program included medical appointments, social activities, and hospital admission.
Table I Characteristics of the participants $(\mathrm{N}=33)$

\begin{tabular}{|c|c|c|}
\hline Characteristics & Mean (SD) & Range \\
\hline Age (years) & $75.03(7.26)$ & $61-92$ \\
\hline Body mass index $\left(\mathrm{kg} / \mathrm{m}^{2}\right)$ & $25.45(3.93)$ & $18.55-33.67$ \\
\hline \multirow[t]{2}{*}{ Duration of symptoms (years) } & $8.97(7.11)$ & $0.2-30$ \\
\hline & $\mathbf{N}$ & $\%$ \\
\hline \multicolumn{3}{|l|}{ Sex } \\
\hline Male & 5 & 15.2 \\
\hline Female & 28 & 84.8 \\
\hline \multicolumn{3}{|l|}{ Marital status } \\
\hline Married & 17 & 51.5 \\
\hline Divorced & 1 & 3.0 \\
\hline Widow/widower & 15 & 45.5 \\
\hline \multicolumn{3}{|l|}{ Educational level } \\
\hline Illiterate & 9 & 27.3 \\
\hline Below primary & 8 & 24.2 \\
\hline Primary & 13 & 39.4 \\
\hline Secondary & 3 & 9.1 \\
\hline \multicolumn{3}{|l|}{ Employment } \\
\hline Unemployed & 33 & 100.0 \\
\hline \multicolumn{3}{|l|}{ Living arrangements } \\
\hline With relatives/friends & 22 & 66.7 \\
\hline Alone & 11 & 33.3 \\
\hline \multicolumn{3}{|l|}{ Type of residence } \\
\hline Public rental housing estate & 26 & 78.8 \\
\hline Private flat & 7 & 21.2 \\
\hline \multicolumn{3}{|l|}{ Financial condition } \\
\hline Supported by social assistance & 6 & 18.2 \\
\hline Not supported by social assistance & 27 & 81.8 \\
\hline \multicolumn{3}{|l|}{ Regular exercise habit } \\
\hline Yes & 23 & 69.7 \\
\hline No & 10 & 30.3 \\
\hline \multicolumn{3}{|l|}{ Body mass index $\left(\mathrm{kg} / \mathrm{m}^{2}\right)$} \\
\hline Normal weight (18.5-23 kg/m²) & 7 & 21 \\
\hline Overweight $\left(23-25 \mathrm{~kg} / \mathrm{m}^{2}\right)$ & 5 & 15 \\
\hline Obese $\left(>25 \mathrm{~kg} / \mathrm{m}^{2}\right)$ & 21 & 64 \\
\hline \multicolumn{3}{|l|}{ Medical follow-up of KOA } \\
\hline Yes & 27 & 81.8 \\
\hline No & 6 & 18.2 \\
\hline \multicolumn{3}{|l|}{ Knee involved } \\
\hline Unilateral & 16 & 48.5 \\
\hline Bilateral & 17 & 51.5 \\
\hline \multicolumn{3}{|l|}{ Use of walking aid } \\
\hline Yes & 15 & 45.5 \\
\hline No & 18 & 54.5 \\
\hline \multicolumn{3}{|l|}{ Medical history } \\
\hline Good past health & 12 & 36.4 \\
\hline Eye/medical problems & 21 & 63.6 \\
\hline
\end{tabular}

Abbreviations: SD, standard deviation; KOA, knee osteoarthritis.

\section{Exercise adherence}

The participants' frequency of exercise practice ranged from $39.4 \%$ to $100 \%$, with a mean percentage of $91.04 \%$ (standard deviation $[\mathrm{SD}]=14.54$ ), indicating an overall high level of adherence to the recommended frequency of exercise practice. Only one participant failed to attain a level of adherence of 
Table 2 Summary of frequency of practice of individual exercise movements

\begin{tabular}{|c|c|c|}
\hline \multirow[t]{2}{*}{ Exercise movement } & \multicolumn{2}{|c|}{ Frequency of exercise practice (\%) } \\
\hline & $\begin{array}{l}\text { Mean (SD) } \\
\text { or N (\%) }\end{array}$ & $\begin{array}{l}\text { Range (possible } \\
\text { range } 0-100 \text { ) }\end{array}$ \\
\hline \multirow[t]{4}{*}{ Raise leg } & $92.15(12.90)$ & $48.4-100$ \\
\hline & $\mathrm{I}(3 \%)$ & $<50$ \\
\hline & $2(6.1 \%)$ & $50-75$ \\
\hline & $30(90.9 \%)$ & $76-100$ \\
\hline \multirow[t]{4}{*}{ Kick back } & 91.54 (I4.22) & $40.3-100$ \\
\hline & $\mathrm{I}(3 \%)$ & $<50$ \\
\hline & $3(9.1 \%)$ & $50-75$ \\
\hline & $29(87.9 \%)$ & $76-100$ \\
\hline \multirow[t]{4}{*}{ Stretch the back of knee } & 91.61 (13.52) & $48.4-100$ \\
\hline & I (3\%) & $<50$ \\
\hline & $3(9.1 \%)$ & $50-75$ \\
\hline & $29(87.9 \%)$ & $76-100$ \\
\hline \multirow[t]{4}{*}{ Stretch the calf } & 91.00 (I5.02) & $38.7-100$ \\
\hline & $\mathrm{I}(3 \%)$ & $<50$ \\
\hline & $3(9.1 \%)$ & $50-75$ \\
\hline & $29(87.9 \%)$ & $76-100$ \\
\hline Raise leg \pm resistance & 91.10 (14.86) & $37.1-100$ \\
\hline \multirow[t]{3}{*}{ from an exercise band } & $\mathrm{I}(3 \%)$ & $<50$ \\
\hline & $3(9.1 \%)$ & $50-75$ \\
\hline & $29(87.9 \%)$ & $76-100$ \\
\hline \multirow[t]{4}{*}{ Squat to half way } & $90.69(15.35)$ & $32.3-100$ \\
\hline & I (3\%) & $<50$ \\
\hline & $3(9.1 \%)$ & $50-75$ \\
\hline & $29(87.9 \%)$ & $76-100$ \\
\hline \multirow[t]{4}{*}{ Rise up from chair } & 89.20 (18.07) & $30.6-100$ \\
\hline & $2(6.1 \%)$ & $<50$ \\
\hline & $3(9.1 \%)$ & $50-75$ \\
\hline & 28 (84.8\%) & $76-100$ \\
\hline
\end{tabular}

Abbreviation: SD, standard deviation.

$50 \%$ to the recommended frequency of exercise practice, while the majority $(\mathrm{N}=29)$ of participants attained a level of adherence of $>75 \%$. Seventeen $(51.5 \%)$ participants adhered fully to the recommended frequency of exercise practice. Table 2 reports the participants' frequency of exercise practice for individual exercise movements. Regarding the reasons for skipping exercise, major reasons included "went out for social activities", "bodily pain", "busy", "tired", and "ill”.

The participants' performance in return-demonstration of the home exercise movements ranged from $28.57 \%$ to $100 \%$, with a mean of $76.71 \%$ ( $\mathrm{SD}=21.75$ ), indicating an overall good performance in mastering of the exercise movements. Among the participants, $87.8 \%(\mathrm{~N}=29)$ obtained a return-demonstration performance score $>50$, while $57.5 \%$ $(\mathrm{N}=19)$ obtained a score $>75$. Moreover, $12 \%(\mathrm{~N}=4)$ of them obtained a full score. Some of the exercises were not well mastered by the majority of participants. For example, the majority of participants $(\mathrm{N}=20 ; 60.6 \%)$ obtained a score $<3$ in stretching the back of knee; hence, it might have
Table 3 Summary of the return-demonstration performance scores for individual exercise movements

\begin{tabular}{lll}
\hline Exercise movement & \multicolumn{2}{l}{$\begin{array}{l}\text { Return-demonstration } \\
\text { performance score }\end{array}$} \\
\cline { 2 - 3 } & $\begin{array}{ll}\text { Mean (SD) } \\
\text { or N (\%) }\end{array}$ & $\begin{array}{l}\text { Range } \\
\text { (possible } \\
\text { range 0-5) }\end{array}$ \\
\hline Raise leg & $4.97(0.174)$ & $4-5$ \\
& $0(0 \%)$ & $0-2$ \\
Kick back & $33(100 \%)$ & $3-5$ \\
& $4.76(0.902)$ & $0-5$ \\
Stretch the back of knee & $1(3 \%)$ & $0-2$ \\
& $32(97 \%)$ & $3-5$ \\
Stretch the calf & $2.00(2.15)$ & $0-5$ \\
& $20(60.6 \%)$ & $0-2$ \\
Raise leg \pm resistance & $13(39.4 \%)$ & $3-5$ \\
from an exercise band & $3.82(1.88)$ & $0-5$ \\
Squat to half way & $8(24.2 \%)$ & $0-2$ \\
& $25(75.8 \%)$ & $3-5$ \\
Rise up from chair & $3.67(2.09)$ & $0-5$ \\
& $9(27.3 \%)$ & $0-2$ \\
& $24(72.7 \%)$ & $3-5$ \\
& $3.52(2.08)$ & $0-5$ \\
Abbreviation & $8(24.2 \%)$ & $0-2$ \\
& $25(75.8 \%)$ & $3-5$ \\
& $4.12(1.27)$ & $1-5$ \\
& $13(39.4 \%)$ & $0-2$ \\
& $20(60.6 \%)$ & $3-5$ \\
\hline
\end{tabular}

Abbreviation: SD, standard deviation.

been a difficult exercise for the participants. Table 3 reports the participants' performance in return-demonstration for individual exercise movements.

\section{Health outcomes}

The majority of the health outcomes improved significantly among the participants, including all the subscale scores (43.2\% for pain, $43.5 \%$ for stiffness, and $50 \%$ for physical functioning) and total scores (45.9\%) of WOMAC, the mental health summary score of SF-12 (16.3\%), degree of ROM (13.5\%), and reduction in time required for TST (15.8\%). Regarding the physical health summary score of SF-12 of the participants, there were improvements, but no statistically significant difference (pretest: $30.14 \pm 17.07$; posttest: $36.36 \pm 16.10 ; P=0.085$ ) between the pretest and posttest physical summary mean scores was attained. Table 4 summarizes the findings of the pretest and posttest health outcome changes of the participants.

\section{Program satisfaction}

The participants' satisfaction score ranged from 75 to 100 with a mean of $90.15(\mathrm{SD}=8.05)$, indicating an overall high level of satisfaction with the exercise program. A summary 
Table 4 Comparisons of health outcomes before and at 3 months after the exercise program using the Wilcoxon signed rank test ( $\mathrm{N}=33$ )

\begin{tabular}{|c|c|c|c|c|}
\hline Health outcome variables & Mean (SD) & Range & $\mathbf{Z}$ & $\begin{array}{l}P \text {-value } \\
\text { (two-tailed) }\end{array}$ \\
\hline WOMAC pain subscale score - pretest & $35.16(23.59)$ & $0.42-86.25$ & $-3.919^{\mathrm{a}}$ & 0.000 \\
\hline WOMAC pain subscale score - posttest & $19.97(19.96)$ & $0.00-75.62$ & & \\
\hline WOMAC stiffness subscale score - pretest & $26.98(23.29)$ & $0.00-84.38$ & $-3.416^{\mathrm{a}}$ & 0.001 \\
\hline WOMAC stiffness subscale score - posttest & $15.22(18.00)$ & $0.00-58.32$ & & \\
\hline WOMAC physical functioning subscale score - pretest & $35.12(24.32)$ & $0.68-88.99$ & $-4.333^{\mathrm{a}}$ & 0.000 \\
\hline WOMAC physical functioning subscale score - posttest & $17.55(14.90)$ & $0.00-52.36$ & & \\
\hline WOMAC total score - pretest & $33.43(22.48)$ & $0.42-86.11$ & $-4.440^{\mathrm{a}}$ & 0.000 \\
\hline WOMAC total score - posttest & $18.08(16.01)$ & $0.00-59.63$ & & \\
\hline SF-1 2 physical health summary score - pretest & $30.4 \mid(17.07)$ & $3.00-63.70$ & $-1.724^{b}$ & $0.085(\mathrm{~ns})$ \\
\hline SF-I 2 physical health summary score - posttest & $36.36(16.10)$ & -7.54 to 62.89 & & \\
\hline SF-I 2 mental health summary score - pretest & $47.21(12.89)$ & $16.90-70.00$ & $-3.100^{b}$ & 0.002 \\
\hline SF-I 2 mental health summary score - posttest & $54.46(11.63)$ & $28.5|-7| .21$ & & \\
\hline Knee range of motion - pretest (degrees) & $93.27(13.27)$ & $67-117$ & $-4.586^{b}$ & 0.000 \\
\hline Knee range of motion - posttest (degrees) & 105.91 (II.19) & $75-130$ & & \\
\hline Timed-Stands Test - pretest (seconds) & $48.82(19.26)$ & $26-120$ & $-2.732^{\mathrm{a}}$ & 0.006 \\
\hline Timed-Stands Test - posttest (seconds) & $41.09(11.85)$ & $25-66$ & & \\
\hline
\end{tabular}

Notes: WOMAC is a visual analog scale. ns: result with $P>0.05$. ${ }^{a}$ Based on positive ranks. ${ }^{b}$ Based on negative ranks.

Abbreviations: SD, standard deviation; WOMAC, Western Ontario and McMaster Universities Osteoarthritis Index; SF-12, I2-item Short Form of the Medical Outcome Study Questionnaire; ns, nonsignificant.

of the responses to the individual items of the satisfaction questionnaire is presented in Table 5.

\section{Qualitative findings}

Six participants, who had completed the one-group pretest posttest study with diverse demographic and clinical background and different responses toward the program, were individually face-to-face interviewed. Table 6 summarizes the participants' characteristics.

Major categories that emerged from the interview data included, (1) satisfaction with the exercise program,

Table 5 Summary of responses to individual items on the satisfaction questionnaire

\begin{tabular}{ll}
\hline Items & Mean (SD) \\
\hline The content of the exercise program is suitable for me & $3.64(0.49)$ \\
The arrangement of frequency and duration of the & $3.52(0.5 \mathrm{I})$ \\
exercise program is appropriate & \\
The amount of material covered in the exercise program & 3.6 I (0.56) \\
is appropriate & \\
The discussion part of the exercise program helps me to & $3.67(0.48)$ \\
integrate the recommended exercise into my daily routine & \\
I am satisfied with the teaching of the coach & $3.88(0.33)$ \\
I can memorize the recommended exercises & $3.39(0.70)$ \\
I think the recommended exercise is not difficult to follow & $3.48(0.5$ I) \\
I have time to practice the recommended exercise in & $3.48(0.5$ I) \\
my daily routine & \\
I am confident that I can develop the habit of practicing & $3.58(0.50)$ \\
the recommended exercise in my daily routine & \\
Overall, I am satisfied with the exercise program & $3.82(0.39)$ \\
\hline
\end{tabular}

Note: Possible item range $=0-4$.

Abbreviation: SD, standard deviation.
(2) mastering of the exercise movements, (3) experience of the exercises' effects, and (4) integration of the exercises into the daily routine.

\section{Satisfaction with the exercise program}

This refers to the informants' satisfaction with the content, arrangement, and teaching of the exercise program. All the informants were in general satisfied with the content, arrangement, and teaching of the program. They did not identify areas for improvement. They commented that the content of the program suited them as it was simple and of the right amount. They also appreciated the simplicity of the exercise movements, which made them easy to learn. They were satisfied with the class frequency and duration, the design which allowed switch of session, the venue because it was convenient, the lively teaching style and patience of the coach, and the use of group teaching approach which enhanced social support among learners. This category is exemplified by the following verbatim responses from the interview data:

I understand the content of the course very well ... It's suitable because it's simple ... I think the content is just right, because I'm stupid and can't learn too much. That's true. The amount is just right. (Informant 5)

The movements they taught are simpler, so it's easy for old people like us to learn. There're other courses that taught us more, but we forgot when we got home after the class. (Informant 1) 


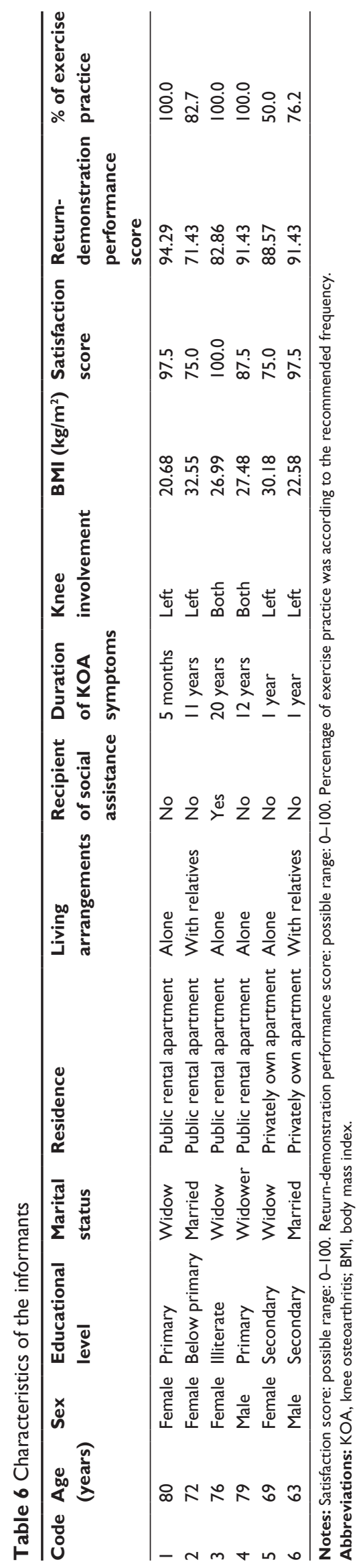

It's enough to have four classes, each lasting one hour ... We go home and practice. Hm ... That's enough. When I'm home ... I refer to the leaflet to learn, and I follow those practices ... It's convenient to have the class held at the centre ... I wouldn't be able to go if it was far away ... The reason is ... It's not easy for me to board or exit public transport vehicles ... Sometimes the vehicles are high, so it's difficult to get down ... So it's okay if it takes place near home! (Informant 2)

I think the instructor taught very clearly. She showed us how the exercise was done.... (Informant 3)

It's better to learn together as a group. We all came here ... We know each other, and it feels like we're a family, a whole. Of course it's better than being alone. It's not fun to come and learn alone, right? (Informant 4)

Sometimes when I forgot, I could look at how others were doing it. It's less embarrassing. (Informant 5)

\section{Mastering of the exercise movements}

This refers to the ability of the participants to perform the exercises correctly. All the informants reported that the return-demonstration and correction of exercise movements in class were useful for learning the exercise. They also required the assistance of the supplementary materials for reviewing the exercise movements at home at the beginning of the course. They claimed that they could gradually memorize all the exercise movements and developed confidence in mastering them. This category is exemplified by the following quotes:

\footnotetext{
We learnt to master it ... If we did it incorrectly, she would teach us so that we're able to do it correctly. (Informant 3 )

I can remember, because there're only a few things. We follow the order, and we're shown pictures. At first, we did it step by step. I mean, at first we certainly had to look at the pictures when we practiced. We couldn't practice without the pictures. We still needed to look at the pictures during the practice, even after doing it 8 or 10 times. After doing it 8 to 10 times, we could remember even without looking at the pictures. (Informant 4)
}

\section{Experience of the exercises' effects}

This refers to the informants' experience of the exercises' effects on various aspects of their physical and psychological health. All the informants reported their experience of feeling alleviated of the symptoms of knee OA including reduction of knee pain, increase in knee flexibility, improvement in leg strength and knee stability, and improvement in 
physical functioning, sleep, and emotions. This category is exemplified by the following verbatim responses from the interview data:

My knees are more flexible, and they're less painful when I walk. I know as I walk. I used to have pain when I took a walk in the park every morning. I could walk down a few flights of stairs at most. After that, I had to hold something for support ... I had to bring an umbrella when I walked down every day. Sometimes, when there was pain, I couldn't walk. Now I don't need to bring an umbrella when I walk down. The most important thing is that after doing this exercise, my knees have become more flexible, and there's no more pain. Walking is more convenient, and I don't need to use an umbrella as a walking aid. (Informant 1)

At first, before I came, I often lost strength and had the tendency to kneel ... This happened, for example, after standing up for a long time ... I haven't noticed this happening recently. The frequency reduced. Another problem was with weather ... Now this is not a problem ... There were two typhoons in the past two months, but I didn't have pain. (Informant 6)

\section{Integration of the exercises into the daily routine}

This refers to the motivation of the informants to adhere to the exercises and the strategies used by them for integrating the exercises into their daily routine. The informants' motivation to adhere to the exercises was influenced by their positive perceptions of exercise in general for maintaining physical independence as well as their positive experience in mastering the exercise skills and experiencing the exercises' effects. Together, these enhanced their commitment to continual practice of the exercises and integration of the exercises into their daily routine. They were willing to set aside some time for doing the exercises. They adjusted the exercise time and venue according to their living context as the exercises were flexible enough that they could do them at various venues. For example, one male informant reported that he could continue the exercise during traveling. The commonalities among the informants were that they usually practiced the exercises as a set in one go and they would integrate the exercise time into their time for watching television. This category is exemplified by the following quotes:

Sometimes I go to the park, sit there and exercise. Sometimes people look at me, and I'd recommend them to do it.... We do it ... at $3 \mathrm{pm}$ or so. (Informant 2)

I usually don't exercise in the morning. I do it in the afternoon and in the evening after dinner. Sometimes I sleep till late in the morning. Sometimes I've different things to do until it's late. That's how time is gone.... I never skip it. I always have to do it. (Informant 3)

You can do it ... There was no problem ... All seven movements can be done when you're watching TV ... I do the exercises when I'm watching TV ... That's more meaningful than just sitting there and watching TV ... I practice the exercises ... I practice the seven movements in one go. (Informant 4)

I'm actually very lazy. I usually don't do it in the morning. I only do it before going to bed.... That's a habit.... That's enough. I'm satisfied as long as I get some exercise [laughter]. That's a habit. I exercise when I'm watching TV ... [laughter]. (Informant 5)

I was once travelling in Macau. I still had to do that exercise. Wherever I got a seat, I practiced it ... It's flexible ... I could do it in hotel or any place with a seat. (Informant 6)

\section{Discussion}

The results of this pilot study reflected the participants' general satisfaction with the exercise program and adherence to the program. The exercise program of this study is different from those in previous studies in that it has been developed by considering the patients' perceptions and experiences of exercise in the development process. ${ }^{23}$ When compared with the results of previous exercise intervention studies in people with knee OA, the tailor-made exercise program in this pilot study appears to have a relatively high level of adherence to the prescribed exercises. ${ }^{7,40,41}$ Therefore, using a tailor-made approach by adopting the patients' view in the design of exercise intervention might be an important conceptual element for practitioners to consider in promoting continual practice of therapeutic exercise among older people with knee OA.

In addition to the high attendance rate, the quantitative results found that the participants were highly satisfied with the program. The qualitative findings added that designs, such as simple exercise movements, a convenient venue, and flexible class arrangement could match participants' needs. The participants also appreciated the flexibility of the prescribed home exercise. In comparison with another study which prescribed exercises in lying position, ${ }^{41}$ the exercise regimen of this study included mainly sitting or standing positions which could facilitate integration of the exercises into daily living. Identifying the popular activities among the target patients may help make prescribed home exercise easy to adhere to. For example, the qualitative findings showed that it was common among the informants to perform the 
exercise during watching television programs which was one of the popular activities among the participants. Requiring less or only handy equipment (resistance band was used in this program) for the exercises may further enhance the participants' motivation to adhere to the exercises.

This study assessed the participants' mastery of the exercise movements, which has implications for exercise safety and therapeutic effects. The results indicated an overall satisfactory performance in mastery of the exercise movements by the participants. The participants' performance in return-demonstration of the exercise movements was better than that of the participants who were dwelling in the same community in another study. ${ }^{41}$ Another previous study of exercise intervention for older people with hip or knee OA assessed the participants' exercise performance at week 8 immediately after the exercise program and found a similar level of performance (an average of 79\% correct performance). ${ }^{42}$ The qualitative findings showed that the participants' mastering of the exercise program began with return-demonstration and corrections in class and then they practiced with the assistance of the pamphlet and poster. The timing of assessing return-demonstration at 3 months after the program provided information for understanding the participants' ability to correctly carry out the exercises over time. Nevertheless, $>40 \%$ of the participants could not obtain a score $>75 \%$ in mastery of the exercise movements; this may indicate some issues about exercise safety and effects. Lack of follow-up within these 3 months could be a concern because OA could flare up during or after exercise; in addition, timely correction of exercise skills might have been missed. Scheduling some follow-up sessions may be required in the first few months and then less frequently for the rest of the year, in order to ensure safety and reinforce the correct exercise movements. Moreover, it may be appropriate to involve the participants' family in the follow-up sessions, who could assist monitoring the knee OA condition and facilitate the mastering process.

The possible therapeutic value of the prescribed exercise was estimated in this pilot study. The comparisons of the participants' knee pain, knee stiffness, and difficulties in physical functioning before and 3 months after the program revealed that all of these key symptoms of knee OA were significantly improved. The significant improvements in objective assessment of the participants' physical functioning including a greater knee ROM and a decrease in time required for performing the TST are consistent to the selfreported measures. According to the qualitative findings, the exercise effects have motivated the participants to further adhere to the exercise regimen. The prescribed exercise demonstrates a slightly better beneficial effect in reducing the participants' symptoms of knee OA and improving their health status in comparison with previous studies. ${ }^{25,43}$ This may be related to the high adherence rate and mastering of the exercise skills.

However, the effect in improving the participants' general health status was significant in the mental aspect but not in the physical aspect. This insignificant finding could be due to the presence of comorbidities. ${ }^{44}$ When knee OA is just one of the clients' health problems, the improvement in knee OA may not be sufficient to change their perceptions of their general health status. Inconsistent results are noted in the literature. ${ }^{41,43,45-48}$

This is a pilot study testing the effects of the program on exercise adherence and health outcomes. This study has several limitations. The evaluation of exercise adherence was limited to 3 months after the exercise program, and thus, the effectiveness of the exercise program in promoting continual practice of the exercises is still inconclusive. In addition, the exercise adherence may have been overestimated as the participants needed to fill up the exercise diary and this may produce an effect of supervision. The one-group pretest and posttest study design, small sample size, and single study site are methodological limitations for understanding the therapeutic effects of the prescribed home exercise on changing the participants' health outcomes. The effect of this exercise program should be subjected to further evaluation by using a more rigorous study approach.

\section{Conclusion}

This pilot study has found that a tailor-made exercise program could enhance program satisfaction, exercise adherence, and mastery of the prescribed exercise. The qualitative findings revealed that the participants' satisfaction with the program may facilitate them to experience the therapeutic effects of the exercise and this further promoted their interest and determination in continual practice of the exercise movements. A positive reinforcing cycle may therefore be formed to promote integration of the exercise into their activities of daily living.

\section{Disclosure}

The authors report no conflicts of interest in this work.

\section{References}

1. Gabriel SE, Michaud K. Epidemiological studies in incidence, prevalence, mortality, and comorbidity of the rheumatic diseases. Arthritis Res Ther. 2009;11(3):229-245. 
2. Murphy L, Schwartz TA, Helmick CG, et al. Lifetime risk of symptomatic knee osteoarthritis. Arthritis Rheum. 2008;59(9):1207-1213.

3. McAlindon TE, Bannuru RR, Sullivan MC, et al. OARSI guidelines for the non-surgical management of knee osteoarthritis. Osteoarthritis Cartilage. 2014;22(3):363-388.

4. Misso ML, Pitt VJ, Jones KM, Barnes HN, Piterman L, Green SE. Quality and consistency of clinical practice guidelines for diagnosis and management of osteoarthritis of the hip and knee: a descriptive overview of published guidelines. Med J Aust. 2008;189(7):394-399.

5. Henriksen M, Hansen JB, Klokker L, Bliddal H, Christensen R. Comparable effects of exercise and analgesics for pain secondary to knee osteoarthritis: a meta-analysis of trials included in Cochrane systematic reviews. J Comp Eff Res. 2016;5(4):417-431.

6. Baker K, McAlindon T. Exercise for knee osteoarthritis. Curr Opin Rheumatol. 2000;12(5):456-463.

7. Pisters MF, Veenhof C, Schellevis FG, Twisk JWR, Dekker J, De Bakker DH. Exercise adherence improving long-term patient outcome in patients with osteoarthritis of the hip and/or knee. Arthritis Care Res (Hoboken). 2010;62(8):1087-1094.

8. Penninx BW, Messier SP, Rejeski WJ, et al. Physical exercise and the prevention of disability in activities of daily living in older persons with osteoarthritis. Arch Intern Med. 2001;161(19):2309-2316.

9. Sullivan T, Allegrante JP, Peterson MG, Kovar PA, MacKenzie CR. One-year follow up of patients with osteoarthritis of the knee who participated in a program of supervised fitness walking and supportive patient education. Arthritis Care Res. 1998;11(4):228-233.

10. Ehrman JK, de Jong A, Sanderson B, Swain D, Swank A, Womack C. ACSM's Resources Manual for Guidelines for Exercise Testing and Prescription. Philadelphia, PA: Lippincott Walliams \& Wilkins; 2010.

11. American College of Rheumatology. Patient education - osteoarthritis. 2016. Available from: http://www.rheumatology.org/I-Am-A/PatientCaregiver/Diseases-Conditions/Living-Well-with-Rheumatic-Disease/ Exercise-and-Arthritis. Accessed February 1, 2008.

12. Arthritis Foundation. Osteoarthritis. 2016. Available from: http://www arthritis.org/living-with-arthritis/exercise/. Accessed March 15, 2008.

13. Golightly YM, Allen KD, Caine DJ. A comprehensive review of the effectiveness of different exercise programs for patients with osteoarthritis. Phys Sportsmed. 2012;40(4):52-65.

14. Fitzgerald GK, Piva SR, Gill AB, Wisniewski SR, Oddis CV, Irrgand JJ. Agility and perturbation training techniques in exercise therapy for reducing pain and improving function in people with knee osteoarthritis: a randomized clinical trial. Phys Ther. 2011;91(4):452-469.

15. O'Grady M, Fletcher J, Ortiz S. Therapeutic and physical fitness exercise prescription for older adults with joint disease: an evidence-based approach. Rheum Dis Clin North Am. 2000;26(3):617-646.

16. Jamtvedt G, Dahm KT, Christie A, et al. Physical therapy interventions for patients with osteoarthritis of the knee: an overview of systematic reviews. Phys Ther. 2008;88(1):123-136.

17. Bosomworth NJ. Exercise and knee osteoarthritis: benefits or hazard? Can Fam Physician. 2009;55(9):871-878.

18. Bennell KL, Hall M, Hinman RS. Osteoarthritis year in review 2015: rehabilitation and outcomes. Osteoarthritis Cartilage. 2016;24(1) $58-70$.

19. Sharma L. Osteoarthritis year in review 2015: clinical. Osteoarthritis Cartilage. 2016;24(1):36-48.

20. Pisters MF, Veenhof C, van Meeteren NL, et al. Long-term effectiveness of exercise therapy in patients with osteoarthritis of the hip or knee: a systematic review. Arthritis Rheum. 2007;57(7):1245-1253.

21. Campbell R, Evans M, Tucker M, Quilty B, Dieppe P, Donovan JL. Why don't patients do their exercises? Understanding non-compliance with physiotherapy in patients with osteoarthritis of the knee. J Epidemiol Community Health. 2001;55(2):132-138.

22. Bennell KL, Dobson F, Hinman RS. Exercise in osteoarthritis: moving from prescription to adherence. Best Pract Res Clin Rheumatol. 2014; 28(1):93-117.
23. Lee FK. Developing and Piloting an Exercise Programme for Older Chinese People with Knee Osteoarthritis in Hong Kong [doctoral thesis]. Hong Kong: The Chinese University of Hong Kong; 2011.

24. Altman RD. Criteria for classification of clinical osteoarthritis. J Rheumatol Suppl. 1991;27:10-12.

25. Baker KR, Nelson ME, Felson DT, Layne JE, Sarno R, Roubenoff R. The efficacy of home based progressive strength training in older adults with knee osteoarthritis: a randomized controlled trial. J Rheumatol. 2001;28(7):1655-1665.

26. Deyle GD, Henderson NE, Matekel RL, Ryder MG, Garber MB, Allison SC. Effectiveness of manual physical therapy and exercise in osteoarthritis of the knee: a randomized, controlled trial. Ann Intern Med. 2000;132(3):173-181.

27. Evcik D, Sonel B. Effectiveness of a home-based exercise therapy and walking program on osteoarthritis of the knee. Rheumatol Int. 2002;22(3):103-106.

28. Fransen M, Crosbie J, Edmonds J. Physical therapy is effective for patients with osteoarthritis of the knee: a randomized controlled clinical trial. J Rheumatol. 2001;28(1):156-164.

29. Hughes SL, Seymour RB, Campbell R, Pollak N, Huber G, Sharma L. Impact of the fit and strong intervention on older adults with osteoarthritis. Gerontologist. 2004;44(2):217-228.

30. Yip YB, Sit JW, Fung KK, et al. Impact of an arthritis self-management programme with an added exercise component for osteoarthritic knee sufferers on improving pain, functional outcomes, and use of health care services: an experimental study. Patient Educ Couns. 2007;65(1):113-121.

31. Bellamy N. WOMAC Osteoarthritis Index: User Guide VIII. 2007. Brisbane, Australia.

32. Bellamy N, Buchanan WW, Goldsmith CH, Campbell J, Stitt L. Validation study of WOMAC: a health status instrument for measuring clinically important patient relevant outcomes following total hip or knee arthoplasty in osteoarthritis. J Orthop Rheum. 1988;1:95-108.

33. Bellamy N, Buchanan WW, Goldsmith CH, Campbell J, Stitt L. Validation study of WOMAC: a health status instrument for measuring clinically important patient relevant outcomes to antirheumatic drug therapy in patients with osteoarthritis of the hip or knee. J Rheumatol. 1988;15(12):1833-1840.

34. Ware JE, Kosinski M, Turn-Bowker DM, Gandeck B. User's Manual for the SF-12v2 ${ }^{\mathrm{TM}}$ Health Survey (with a Supplement Documenting the $S F-12^{\circledR}$ Health Survey). Lincoln, RI: QualityMetric Incorporated; 2007.

35. Lam CLK, Lauder IJ, Lam TP, Gandek B. Population based norming of the Chinese (HK) version of the SF-36 health survey. Hong Kong Pract. 1999;21(10):460-470.

36. Gandek B, Ware JE, Aaronson NK, et al. Cross-validation of item selection and scoring for the SF-12 Health Survey in nine countries: results from the IQOLA Project. International Quality of Life Assessment. J Clin Epidemiol. 1998;51(11):1171-1178.

37. Jenkinson C, Layte R, Jenkinson D, et al. A shorter form health survey: can the SF-12 replicate results from the SF-36 in longitudinal studies? J Public Health Med. 1997;19(2):179-186.

38. Resnick B, Nahm ES. Reliability and validity testing of the revised 12-item Short-Form Health Survey in older adults. J Nurs Meas. 2001; 9(2):151-161.

39. Lam CL, Tse EY, Gandek B. Is the standard SF-12 health survey valid and equivalent for a Chinese population? Qual Life Res. 2005; 14(2):539-547.

40. Ettinger WH Jr, Burns R, Messier SP, et al. A randomized trial comparing aerobic exercise and resistance exercise with a health education program in older adults with knee osteoarthritis: the Fitness Arthritis and Seniors Trial (FAST). JAMA. 1997;277(1):25-31.

41. Tsang KWE. A Community Nurse-Led Protocol for Clinical Knee Osteoarthritis in Older Persons [master's thesis]. Hong Kong: The Chinese University of Hong Kong; 2003.

42. Schoo AMM, Morris ME, Bui QM. The effects of mode of exercise instruction on compliance with a home exercise program in older adults with osteoarthritis. Physiotherapy. 2005;91(2):79-86. 
43. Wong YK, Hui E, Woo J. A community-based exercise programme for older persons with knee pain using telemedicine. J Telemed Telecare. 2005;11(6):310-315.

44. van Dijk GM, Veenhof C, Schellevis F, et al. Comorbidity, limitations in activities and pain in patients with osteoarthritis of the hip or knee. BMC Musculoskeletal Disord. 2008;9:95.

45. Bennell KL, Hinman RS, Metcalf BR, et al. Efficacy of physiotherapy management of knee joint osteoarthritis: a randomized, double blind, placebo controlled trial. Ann Rheum Dis. 2005;64(6):906-912.

46. Chaipinyo K, Karoonsupcharoen O. No difference between home-based strength training and home-based balance training on pain in patients with knee osteoarthritis: a randomized trial. Aust J Physiother. 2009; 55(1):25-30.
47. Jenkinson CM, Doherty M, Avery AJ, et al. Effects of dietary intervention and quadriceps strengthening exercises on pain and function in overweight people with knee pain: randomized controlled trial. $B M J$. 2009;339:b3170.

48. Thomas KS, Muir KR, Doherty M, Jones AC, O’Reilly SC, Bassey EJ. Home based exercise programme for knee pain and knee osteoarthritis: randomized controlled trial. BMJ. 2002;325(7367):752-756.

\section{Publish your work in this journal}

Clinical Interventions in Aging is an international, peer-reviewed journal focusing on evidence-based reports on the value or lack thereof of treatments intended to prevent or delay the onset of maladaptive correlates of aging in human beings. This journal is indexed on PubMed Central, MedLine,
CAS, Scopus and the Elsevier Bibliographic databases. The manuscript management system is completely online and includes a very quick and fair peer-review system, which is all easy to use. Visit http://www.dovepress. com/testimonials.php to read real quotes from published authors. 